\title{
A Novel Based Wind/Solar Electric Vehicles for Green and Clean Environment
}

\author{
Adeel Saleem*, Nain Liu, Hu Junjie, Atif Iqbal, Muhammad Aftab Hayyat \\ School of Electrical \& Electronic Engineering, North China Electric Power University, Beijing, China. \\ * Corresponding author. Tel.: +8613241578740; email: adeel.saleem@ncepu.edu.cn \\ Manuscript submitted November 5, 2019; accepted February 7, 2020. \\ doi: 10.17706/ijcce.2020.12.2.93-101
}

\begin{abstract}
As the world population is increasing day by day and there is an increase in the use of energy in the same order, so it is essential to keep our energy resources very high to meet the demand. It is the fact that due to the rapid depletion of fossil fuel resource worldwide, it became essential to search for alternative sources of energy. For transportation mode, the electric vehicles found the difficulty of charging the batteries after propelling few kilometers. This paper proposes a wind/solar based electric vehicle which can charge the batteries on mobility. It will increase its mileage as well as helping to keep the environment green and clean. The proposed model of the electric vehicle is driven on the same principles as used in electric vehicles. The top (roof/bonnet) of the vehicle is equipped with $420 \mathrm{~W}$ flexible solar panel, the windscreen and four windows covered by a $410 \mathrm{~W}$ flexible solar panel which could only be utilized while on parking. The surrounding of the area is equipped with $460 \mathrm{~W}$ flexible solar panel; a $400 \mathrm{~W}$ micro wind turbine is located at the front of the vehicle behind the condenser, the combination of small wind turbines adjusted between the two layers of vehicle external body and PV panels. MATLAB/SIMULINK model presented that by utilizing the combination of PV panel and micro wind turbine provide extra power to charge the $30.7 \mathrm{kWh}$ Lithium (Li)-ion battery and is increasing the range up to several kilometers, while the model runs for one sunny day.
\end{abstract}

Key words: Electric vehicle, clean energy, green environment, wind/solar based vehicle.

\section{Introduction}

Population growth rate increases every day and there is an increase in the transportation modes. The petrol/diesel/gasoline powers vehicles, so they must have the combustion engine. Due to the combustion of fossil fuels in the industries, there is an increase in carbon number which destroying the ozone layer. So, like the industries, if there is no one to stop the petrol/diesel vehicles, then there will be a very adverse effect on earth like acid rain and air pollution [1]. Combustion engine vehicles are replacing by electric vehicles very rapidly, which utilizes an electric motor to provide the power needed for propulsion, and these are more efficient compared to combustion engine vehicles [2]. Electric vehicles are charged through charging stations which are interconnected with the national grid and increasing the load demand. The national grid is feeding by the power plants which are running on fossil fuels then it's mean the electric vehicles consuming the fossil fuels by the indirect way and in this case, they are also decreasing there efficiency by not using combustion engines directly. So the power sources which feed the electric vehicle should be reliable, environment-friendly and economical [3], [4].

Electric vehicles are facing the problem of charging their batteries after propelling a few kilometers. After 
survey of the current literature show that the research work emphasizes the performance improvement of the battery, aging of the battery [5], thermal management on batteries [6], wireless charging of the batteries [7], resonant converter based battery charging [8], charging of the batteries with renewable energy resources [9] to minimize the load demand on the grid.

There is a need of renewable energy sources that the electric vehicle can be charged while on mobility or standby, but it should be environment-friendly, which keeps the environment green and clean [4], [10]. This study proposes a Wind/solar electric vehicle which can be charged by the solar energy and as well as using the wind energy to increase its range. This proposed model uses two energy resources so that any one of source fails other sources will keep generating the electricity to charge up batteries [11]. For example, while there is a sunny day, then the wind/solar electric vehicle charged by the solar PV panel and while in mobility, it also is charged by the wind energy [10]. Now if there is not a sunny day or the cloudy day, then it can be charged by the wind turbines.

On the other hand, in good weather condition, both sources can be used at the same time. It can transfer its power to other electric vehicles as well as to the grid in case of surplus energy. In adverse circumstances, if there will be no sunlight and not enough wind to run the wind turbines, it can be charged by the electric vehicle charging stations. In short, these have many advantages over the fossil fuels engine cars, as well as the electric vehicles and solar cars.

\section{Configuration of Proposed Wind/Solar Electric Vehicles}

Wind/Solar electric vehicle driven by one or more electric motors, using electrical energy stored in rechargeable batteries which provide the power to the motor to run the car forward or backward. To fulfill the power demand for the motors, need to select the PV panels and micro wind turbines in a very efficient way and Fig. 1 Shows the configuration of the Wind/Solar electric vehicle.

\subsection{Solar Energy and Selection for PV Panel}

The solar energy is the most pollution-free energy which is generated by the radiations of the sun and this energy has been called the superior energy [12]. It is pollution free and affordable energy with low maintenance cost along with the average amount of the solar radiations on the earth is 8000 times higher than the average world energy consumption [12].

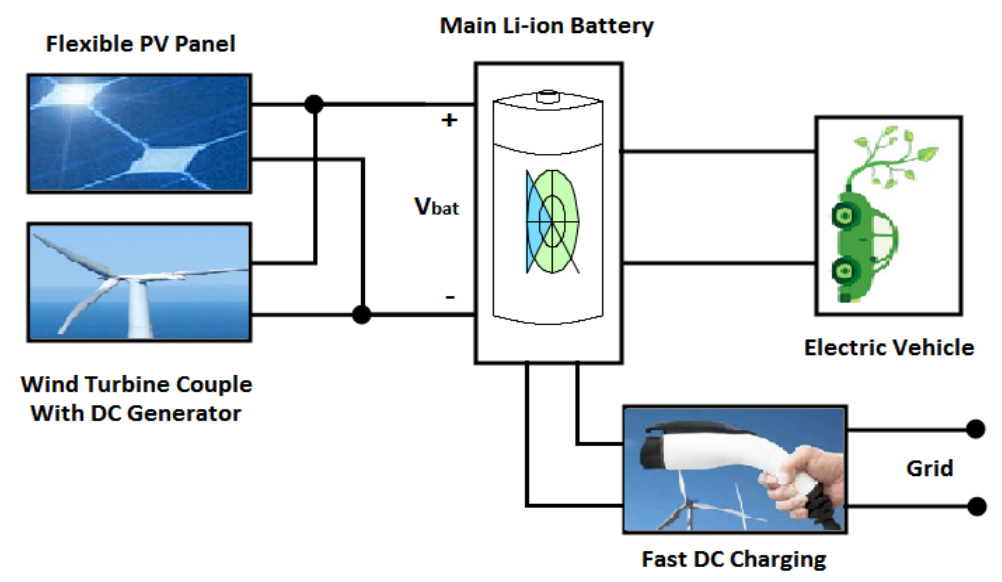

Fig. 1. Configuration for the wind/solar electric vehicle.

The solar array uses photovoltaic cells (PV cells) to convert sunlight into electricity. When sunlight (photons) strikes PV cells, they excite electrons and allow them to flow, creating an electric current. PV cells are made of semiconductor materials (mainly silicon) and alloys of indium, gallium, and nitrogen. 


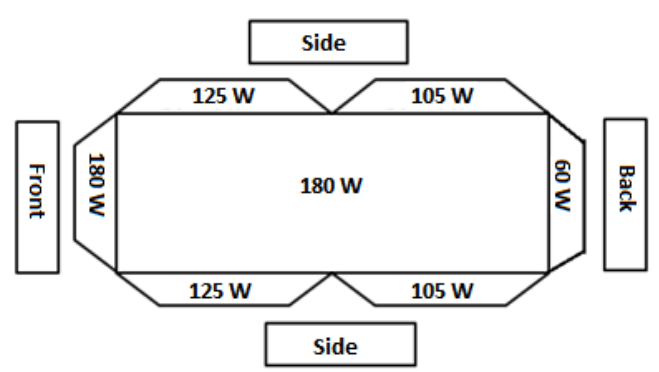

Fig. 2. Projection view of PV panel.

There are two main types of PV panels available as mono-crystalline and Polycrystalline [13]. Scientific results show that the mono-crystalline type of the solar cell has the high electric efficiency than the other type of solar cell (polycrystalline) [13]. So, for the Wind/Solar Electric vehicle, the mono-crystalline is the optimal selection and the projection view of the solar panel can be equipped on an average size vehicle is shown in Fig. 2. The amount of power generated from the solar cells is all depend upon the covered area of these cells and secondly the contact hours with the direct sunlight.

To obtain the maximum power from the installed PV panel, factors affecting the efficiency of the PV panels like the direction of PV panel, irradiance, temperature, angle and the shade on it should be considered [14]. The output will vary according to the installed capacity of the solar cells. The windscreen and the other windows of the car are equipped with the transparent solar cell to get more power from the sun to make this electric vehicle more capable.

The transparent solar cells only allow the visible light to pass on and generate electrical current by capturing the non-visible bandwidth of the light which comes from the sun. Table 1 shows that how much flexible solar panel can be equipped on an average size vehicle and the amount of maximum power can be generated by capturing the sun heat along a day.

Table 1. Maximum Power Output from a Solar Cell

\begin{tabular}{|c|c|c|c|c|}
\hline Power (W) & Weight(Kg) & Size(mm) & $\begin{array}{c}\text { Voltage at } \\
\boldsymbol{P} \boldsymbol{m a x}(\mathrm{V})\end{array}$ & $\begin{array}{c}\text { Current at } \\
\boldsymbol{P} \boldsymbol{\operatorname { m a x }}(\mathrm{A})\end{array}$ \\
\hline 25 & 0.57 & $555^{*} 277$ & 17.6 & 1.42 \\
\hline 30 & 0.75 & $535^{*} 375$ & 17.5 & 1.71 \\
\hline 80 & 1.85 & $922^{*} 540$ & 15.4 & 5.19 \\
\hline 100 & 2 & $1050^{*} 540$ & 17.7 & 5.70 \\
\hline 110 & 2.25 & $1175^{*} 540$ & 19.55 & 5.63 \\
\hline 180 & 3 & $1305^{*} 796$ & 16.80 & 10.71 \\
\hline
\end{tabular}

The electric vehicle with an average size can be equipped with $880 \mathrm{~W}$ with the flexible solar panel and $410 \mathrm{~W}$ under the windscreen and the windows of the vehicle while it is parked with an additional weight of $25 \mathrm{~kg}$ and thickness of $3 \mathrm{~mm}$. The capital cost requires for installation of a PV panel is about 4,500 Yuan. The electric vehicle should be good looking for this the solar cells can be embedded in the material of the car while manufacturing otherwise with ugly shaped vehicles will not have a bright future.

\subsection{Wind Energy and Selection of the Micro Wind Turbine}

The pollution free generation is the growing global awareness, so changing the trend towards the wind energy, which has the benefit of lower cost and higher availability [15]. Wind energy is present almost 24 hours of the day, but airspeed can vary according to the weather condition and has no CO2 emissions [16], [4]. The initial cost is also less for this system and the production of electricity from wind energy depends upon 
the speed of wind [10]. The energy is extracted from the wind by use of windmill/turbine in which an alternator is connected to the intake valve that converts the kinetic energy of moving the turbine to electrical energy.

For this purpose, there are two types of the wind turbines while the vertical axis winds turbines (VAWT) or the horizontal axis wind turbines (HAWT). VAWT is the type of wind turbine where the rotor shaft is set vertically and all the other main components present at the base of the turbine. VAWT has several advantages over HAWT like pleasant appearance, quiet operation, tall towers not needed for installation of the wind turbine, a yaw mechanism is not necessary to turn with wind direction along with simple to install and maintain [17]. It is not required to be pointed into the wind and can be installed closer together in wind farms and allowing more in a given space [18]. That is not just because of their smaller size but due to the slowing effect on the air that horizontal air wind turbines have, forcing designers to separate them by ten times their width. So, for the Wind/Solar electric vehicle, the VAWT is the optimal selection. Fig. 3 shows the possible placement for the micro wind turbines.

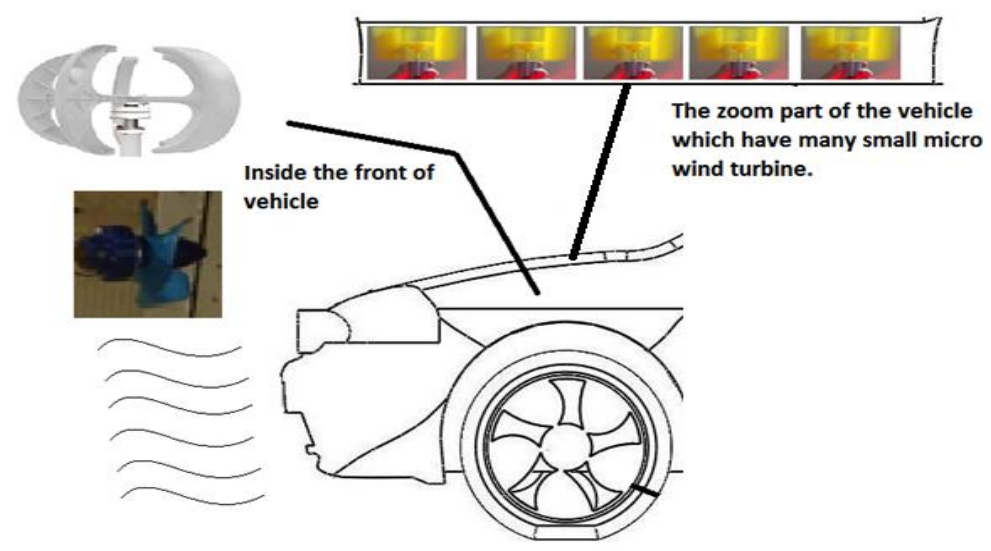

Fig. 3. Placement for the micro wind turbines.

The power produced by the wind turbine depends on the wind speed, which is proportional to power generation while the vehicle stationary or in mobility. So, the power generated from wind should be fluctuating and hence totally depends on the vehicle speed and the wind blowing speed.

For a particular case, the wind-generated power from the wind turbine is determined by the air captured by the blades, and it differs for a small wind turbine in series and the micro wind turbine. Theoretically, the power generated from the wind turbine, $P$ can be found from the Equation 1 [17], [19], where $A$ is the capture area $\left(A=\pi(D / 2)^{2}\right), \rho=1.225 \frac{\mathrm{Kg}}{\mathrm{m}^{3}}$ is the density of air and $V$ is the wind speed.

$$
P=\frac{1}{2} A \rho V^{3}
$$

Vertical axis wind turbine spins like a top with an axis of rotation perpendicular to the wind [20]. The available power can be found as

$$
P=\frac{1}{2} C_{p} A \rho V^{3}
$$

where, $C_{p}$ is the power coefficient. The maximum value of the coefficient of performance is 0.593 , determine by a fluid mechanics constraint known as the Betz Limit [21]. The electrical power which generated from the generator is less than the power captured by the rotor, which is due to the losses of the gearbox and generator. So the final equation for the electric power is as follow [17].

$$
P^{T}=\frac{1}{2} C_{p} \eta_{g} \eta_{b} A \rho V^{3}
$$


where $\eta_{g}$ and $\eta_{b}$ are efficiencies for the gearbox and the generator and are typically $90-95 \%$ and $50 \%$ respectively [17]. The expected hourly generated electric power shown as in Table 2 for area captured by the blades of the wind turbine is about 0.5 meter, while the coefficient of performance is 0.3 and efficiencies are 0.96 .

Table 2. Energy Output on Different Wind Speed

\begin{tabular}{|c|c|c|c|}
\hline \multicolumn{2}{|c|}{ Wind Speed(m/s) } & \multicolumn{2}{c|}{ Hourly Energy Output (Wh) } \\
\hline 0 & 14 & $\mathbf{0}$ & 93.296 \\
\hline 2 & 16 & $\mathbf{0 . 1 9 6 2}$ & 139.264 \\
\hline 3 & 18 & $\mathbf{0 . 9 1 8}$ & 198.288 \\
\hline 4 & 20 & $\mathbf{2 . 1 7 6}$ & 272 \\
\hline 5 & 22 & $\mathbf{4 . 2 5}$ & 362.032 \\
\hline 6 & 24 & $\mathbf{7 . 3 4 4}$ & 470.016 \\
\hline 8 & 26 & $\mathbf{1 7 . 4 0 8}$ & 597.58 \\
\hline 10 & 28 & $\mathbf{3 4}$ & 746.368 \\
\hline 12 & 30 & $\mathbf{5 8 . 7 5}$ & 918 \\
\hline
\end{tabular}

The power output depends upon the speed of the wind and number of small turbines equipped on the vehicle as shown in Fig. 4 that how much small wind turbines can be equipped on an average size electric vehicle. For this particular case install one micro wind turbine in the front of the vehicle behind the condenser and 505 small wind turbines on the upper body of the vehicle between the layer of the vehicle with the additional weight of $15 \mathrm{~kg}$ and layer thickness of $100 \mathrm{~mm}$. The capital cost requires for installation of the wind turbine is about 15,000 Yuan.

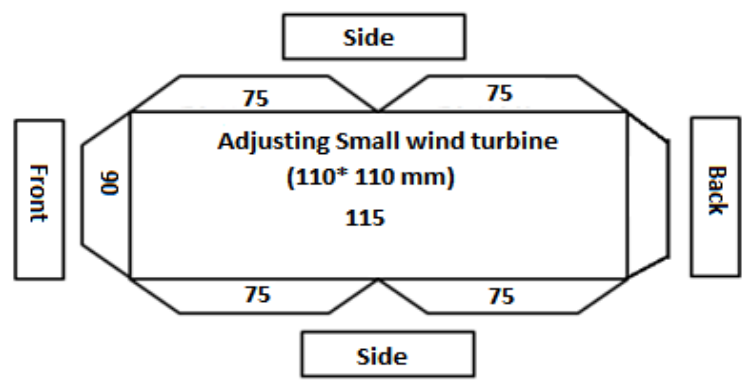

Fig. 4. Projection view of small wind turbines.

\section{Simulation Results for the Proposed Wind/Solar Electric Vehicle}

The proposed model for an electric vehicle is built in the MATLAB/SIMULINK to verify the results. The simulation is run in different modes, as shown in Table 3. For simulation purpose the Nissan 2017 taking as a reference vehicle which gives $9.25 \mathrm{~km}$ by consuming 1 kilo-watt-hr while on $61 \mathrm{~km} / \mathrm{hr}$. In this particular case, the battery vehicle range is $30.72 \times 9.25=284 \mathrm{~km}$. For one hour of driving the energy required from the battery is equal to $\frac{1 \mathrm{kwh} \times 61 \mathrm{~km}}{9.25 \mathrm{~km}}=6.60 \mathrm{kwh}$. To limit the drive cycle with the speed of $61 \mathrm{~km} / \mathrm{hr}$, the current should be Current $(A)=\frac{6.60 \mathrm{kwh}}{24 \mathrm{~V}}$ as shown in Fig. 5 . 


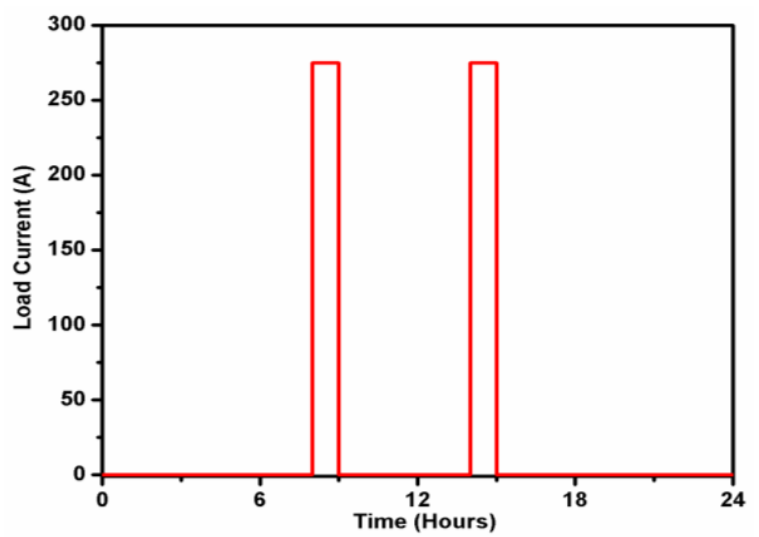

Fig. 5. Drive cycle for the vehicle for one day.

There are two types of wind turbine coupled with PMDC generator is used for simulation purpose. The first type of PMDC generator coupled with wind turbine of 5.5V@100mA is used and the \% state of charge of the battery is shown in Fig. 6(a). The second type of PMDC generator of 12V@3A is used and the results are shown in the Fig. 6(b). There is a trade-off between the thickness of the outer body of the vehicle and power produced by it.
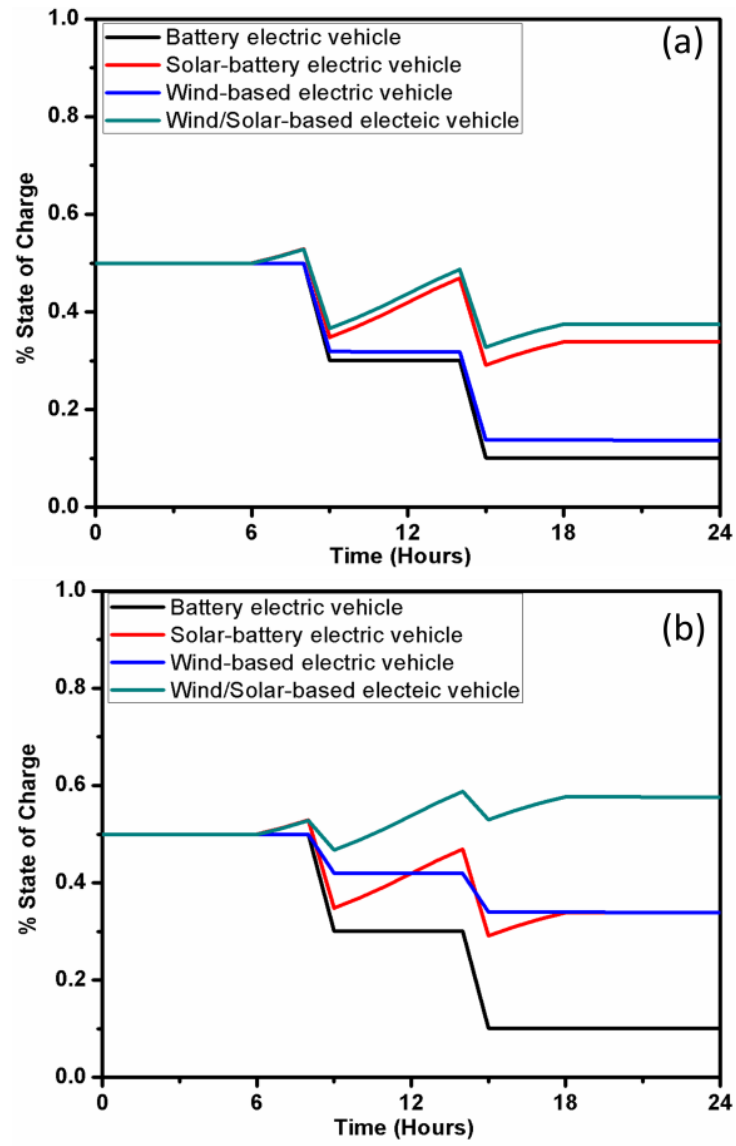

Fig. 6. \% State of charge for the battery, (a) Electrical Vehicle outer Body thickness (110 mm), (b) Electrical Vehicle outer roof body thickness $(150 \mathrm{~mm})$ and other body thickness $(110 \mathrm{~mm})$.

The battery is initially charged by $50 \%$ and the simulation is run for one sunny day, so the range for the battery according to specification is $142 \mathrm{~km}$. Wind turbines are assumed to work only when the vehicle is in 
mobility and the simulated results have shown the remaining state of charge and the range for the vehicle as in Table 3. The calculation for the remaining range is extracted by the percentage of the remaining state of charge of the battery multiply with the total range of the vehicle when fully charged, as shown in equation 4.

$$
\text { Remaining Range For Battery }=10 \% \times(284)
$$

Table 3. Comparison between the Different Modes of Electric Vehicle

\begin{tabular}{|c|c|c|c|}
\hline Type of Electric Vehicle & $\begin{array}{c}\text { \% State of Charge } \\
\text { Left }\end{array}$ & $\begin{array}{c}\text { Remaining Range } \\
(\mathrm{Km})\end{array}$ & $\begin{array}{c}\text { Speed For } \\
\text { Vehicle } \\
\text { (Km/hr) }\end{array}$ \\
\hline \multicolumn{3}{|c|}{ Electrical Vehicle outer Body thickness (110 mm) } \\
\hline Battery/PV/Wind & $38 \%$ & 106 & 61 \\
\hline Battery/PV & $34 \%$ & 96 & 61 \\
\hline Battery/Wind & $14 \%$ & 38 & 61 \\
\hline Battery & $10 \%$ & 28 & 61 \\
\hline Electrical Vehicle outer roof body thickness (150 mm) and other body thickness (110 mm) \\
\hline Battery/PV/Wind & $58 \%$ & 164 & 61 \\
\hline Battery/PV & $34 \%$ & 96 & 61 \\
\hline Battery/Wind & $34 \%$ & 96 & 61 \\
\hline Battery & $10 \%$ & 28 & \\
\hline
\end{tabular}

Wind generation from the micro turbines at the rest position or on parking it depends on the wind speed. If the wind speed is about $35 \mathrm{~km} / \mathrm{hr}$ or considering the half of the electrical vehicle speed on which all the simulation is run and consider wind for half of the day on average then electric vehicle battery can give extra range of $34 \mathrm{~km}$ on the speed limit of $61 \mathrm{~km} / \mathrm{hr}$ for one day with the electric vehicle outer body thickness of $150 \mathrm{~mm}$. As the thickness of the electrical vehicle roof is increases to $150 \mathrm{~mm}$, then $141 \mathrm{~km}$ can be produced just on parking.

\section{Conclusion}

The electric vehicle is an optimal choice for automobiles than conventional systems to keep the environment green and healthy and as well as it is very economical. Wind/Solar electric vehicle has much more benefits as compared to conventional electric vehicles, solar energy cars and as well the combustion engine cars. It is seen clearly that how much energy can be harvested by the combination of micro wind turbines and the solar cell. This useful energy which produced by the combination of these two renewable energy resources helps to increase the mileage of the electric vehicles. The sharing of the recharged batteries for the electric vehicles will be the future recommendation for this research. The standard size of rechargeable batteries will be introduced in the market with an android application which is adopted by all the electric vehicles and the sellers. It is much safer for the environment because it doesn't produce any devastating emission and a harmful waste product like conventional cars do.

\section{Conflict of Interest}

The authors declare no conflict of interest.

\section{Author Contributions}

Adeel Saleem contributed in all parts of this paper such as collect and process data, construct the model and interpret the results, write up of the paper. Nain Liu and Hu Junjie contributed to analyze and supervise all the work. Atif Iqbal and Muhammad Aftab Hayyat help to collect data and reviewing the paper. 


\section{References}

[1] Energy Technology Support Unit (Great Britain). (1994). An Assessment of Renewable Energy for the UK. London: HMSO.

[2] Fathabadi, H. (2017, Jan.). Novel solar powered electric vehicle charging station with the capability of vehicle-to-grid. Sol. Energy, 142, 136-143.

[3] Mppt, T., \& System, P. (2015). Wind solar hybrid energy conversion system-Literature review. International Journal of Scientific Research(IJSR), 2277, 5-6.

[4] Nehrir, M. H., et al. (2011, Oct.). A review of hybrid renewable/alternative energy systems for electric power generation: Configurations, control, and applications. IEEE Trans. Sustain. Energy, 2(4), 392-403.

[5] Casals, L., Gonzalez, A. M. S., Garcia, B., \& Llorca, J. (2016). PHEV battery aging study using voltage recovery and internal resistance from onboard data. IEEE Trans. Veh. Technol., 65(6), 4209-4216.

[6] Fathabadi, H. (2014, Jun.). High thermal performance lithiumion battery pack including hybrid active-Passive thermal management system for using in hybrid/electric vehicles. Energy, 70, 529-538.

[7] Zeng, H., Yang, S., \& Peng, F. Z. (2017, Aug.). Design consideration and comparison of wireless power transfer via harmonic current for PHEV and EV wireless charging. IEEE Trans. Power Electron., 32(8), 5943-5952.

[8] Deng, J., Mi, C. C., Ma, R., \& Li, S. (2015). Design of LLC resonant converters based on operation-mode analysis for level two PHEV battery chargers. IEEE/ASME Trans. Mechatronics, 20(4), 1595-1606.

[9] Peng, M., Liu, L., \& Jiang, C. (2012, Apr.). A review on the economic dispatch and risk management of the large-scale plug-in electric vehicles (PHEVs)-penetrated power systems. Renew. Sustain. Energy Rev., 16(3), 1508-1515.

[10] Bull, S. R. (2001). Renewable energy today and tomorrow. Proceedings of the IEEE, 89(8), 1216-1226.

[11] Rakeshkumar, B. S. (2015). Wind solar hybrid energy conversion system-Literature review. International Journal of Scientific Research, 4(6), 231-232.

[12] Mousavi, S. A., et al. (2018, Jan.). Important solar parameters in installing solar cells: Case study of Zanjan city in Iran. Proceedings of the 5th Int. Conf. Renew. Energy Gener. Appl. (pp. 107-111).

[13] Horompoli, B., \& Racz, E. (2018). Statistical analysis of power measurements made on mono- and polycrystalline solar cells. Proceedings of the 2018 IEEE 16th World Symp. Appl. Mach. Intell. Informatics (pp. 000149-000154).

[14] Babur, Y. (2004, July). Determining optimum tilt angles and orientations of photovoltaic panels in Sanliurfa, Turkey. Renew. Energy, 29(8), 1265-1275.

[15] Goli, P., \& Shireen, W. (2015). Control of PREY charging facilities integrated with small scale wind turbine. Proceedings of the 2015 IEEE Transp. Electrif. Conf. Expo, ITEC 2015.

[16] Working paper. (2009). Prospects for energy storage in decarbonised power grids. Retrieved from https://www.osti.gov/etdeweb/biblio/21248888

[17] Ahad, J. S., \& Shakil, A., American, T., \& Energy, W. (2013). Hypothetical discussion on windmill. Proceedings of the International Conference on Electrical Information and Communication Technology (EICT).

[18] Eriksson, S., Bernhoff, H., \& Leijon, M. (2008, Jun.). Evaluation of different turbine concepts for wind power. Renew. Sustain. Energy Rev., 12(5), 1419-1434.

[19] Grogg, K. (2005). Harvesting the wind: The physics of wind turbines. Phys. Astron. Comps Pap., 1-44.

[20] Johnson, K. E. (2004, Aug.). Adaptive torque control of variable speed wind turbines. National Renewable Energy Lab., Golden, CO (US).

[21] Burton, T., Sharpe, D., Jenkins, N., \& Bossanyi, E. (2001). Wind Energy Handbook. Chichester, UK: John Wiley \& Sons, Ltd. 
Copyright (C) 2020 by the authors. This is an open access article distributed under the Creative Commons Attribution License which permits unrestricted use, distribution, and reproduction in any medium, provided the original work is properly cited ( $\underline{\text { C BY } 4.0}$ ).

Adeel Saleem was born on 18th November, 1990 in Lahore, Pakistan. He did his bachelor's and master degree of electrical engineering from the University of Lahore, Pakistan with distinguish. Currently, he is doing his $\mathrm{PhD}$ in electrical engineering from the North China Electric Power University, Beijing, China. Now the author's memberships are engaged in scientific research projects related to green and clean energy. 